\title{
Alternative diagnosis for pain in patients who underwent appendectomies for normal appendices and the incidence of negative appendectomies
}

\author{
Ali M. Muhammed*, Hiwa O. Ahmed** \\ * General Surgeon, Sulaimaniyah Teaching Hospital; \\ ** College of Medicine, University of Al-Sulaimaneyah.
}

(Ann. Coll. Med. Mosul 2011; 37 (1 \& 2): 80-86).

Received: $9^{\text {th }}$ Jun 2010; Accepted: $5^{\text {th }}$ Jun 2011.

\begin{abstract}
Background and objectives: Some gastrointestinal and genitourinary tract pathologies can simulate clinical features of acute appendicitis; we aim to determine the alternative diagnosis for the pain in which appendicitis was considered, and to find the incidence of negative appendectomies in our practice.

Methods: An observational study, including 558 patients, who underwent an appendectomy at $\mathrm{Al}$ Sulaimaniyah Teaching Hospital (STH) from the $2^{\text {nd }}$ of January to the $30^{\text {th }}$ of June 2009. Only patients who underwent urgent appendectomy and the specimen subjected to tissue examination were included. Appendices were labeled acutely inflamed when, macroscopically there were injections of mucosa, fibrinous or purulent film, edematous or necrotic changes of the wall and blood or pus on opening the appendix.
\end{abstract}

Results: Most of the patients were young between 20-40 years age with median age of $22 \pm 7.7$ years. Other pathologies presented in patients with macroscopically normal appendices, included 35 $(6.27 \%)$ patients had purulent peritoneal fluids occured in young female with tubo-ovarian infections, $12(2.15 \%)$ patients had mesenteric lymphadenitis and $37(6.63 \%)$ patients had rupture Graafian follicles. Histologically normal appendix was present in $178(31.89 \%)$ patients, 61 (10.93\%) of them were males and $117(20.96 \%)$ were females.

Conclusion: Normal appendectomies were found in $32 \%$ of the patients, more frequently in young female patients, undergoing early (within 6 hrs since the pain) appendectomy, with the most common alternative diagnosis of tubo-ovarian infections.

Keywords: Acute appendicitis, alternative diagnosis, normal appendix.

الخلاصة

هدف البحث: بعض الحالات المرضية في الجهاز الهضمي والبولي -التناسلي يمكن ان تسبب أعراض مشابهة لالتهاب

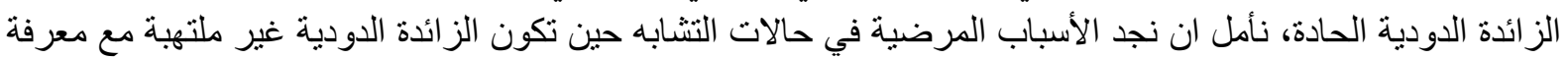
مدى شيوع هذه الظاهرة في عملنا الجر احي. طرق البحث: شمل البحث (001) مريضا، أجريت لهم فمل عمليات استنئصال الزائدة الدودية، في المستشفى التعليمي في

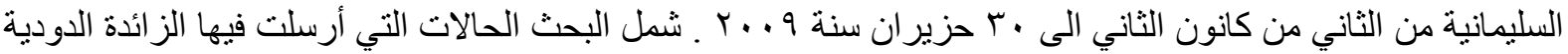
للفحص النسيجي فقط، وخلال العملية اعتبرت الزائدة الدودية ملتهبة عبر مشاهدة علامات عينية مثل نورم الغشاء الخارجي، وجود تليف و التصاق او طبقة قيحية او موات على جدار الزائدة الدودية، او وجود دم او قيح عند فتح الزائدة الدودية. 


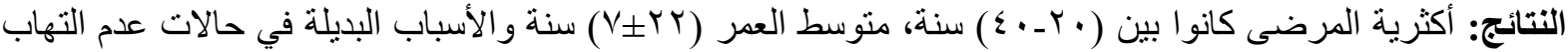

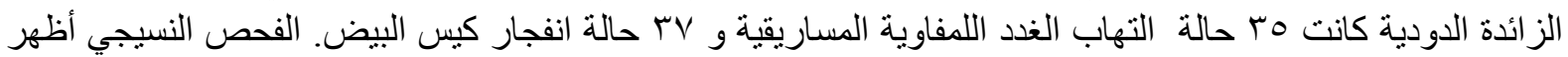

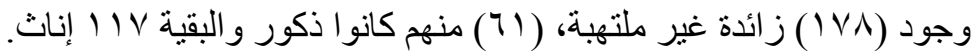

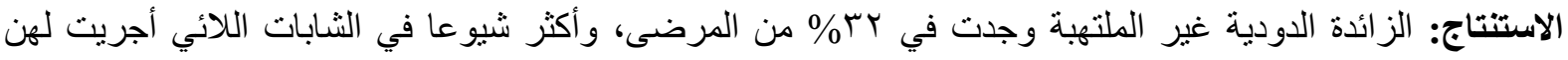

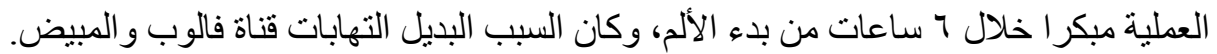

A cute appendicitis is the most common cause of urgent abdominal surgery ${ }^{(1)}$, the accuracy of a clinical diagnosis of acute appendicitis based on patient's history and physical examination ranges from $70 \%$ to $84 \%$, because other gastrointestinal and genitourinary tract abnormalities can present similarly. (2) A delay in diagnosis or an incorrect diagnosis causes serious complications. ${ }^{(3,4)}$ Although history and physical examination results remain the cornerstone of the diagnosis of acute appendicitis, many additional adjuncts have been proposed to increase diagnostic accuracy ${ }^{(3)}$.

These include laboratory investigations like WBC count, C reactive protein, serum markers, scoring systems, ultrasonography, computed tomographic (CT) scanning, and laparoscopy ${ }^{(3,5)}$, but no laboratory or radiological test is $100 \%$ accurate. ${ }^{(6)}$

Unfortunately, the clinical benefit of none of the scores has been tested in an adequate controlled study, ${ }^{(7,8)}$ negative appendectomy rate of $7 \%$ was found. ${ }^{(7)}$

Regarding laboratory investigations, normal appendices were found in $13.4 \%$ and $32.5 \%$ of the patients who had high and normal white blood cell counts, respectively. ${ }^{(9)}$

Both ultrasonography (US) and computed tomography (CT) help in diagnosis of acute appendicitis ${ }^{(10)}$ Sonography is preferred more than CT; as the initial imaging study for young, female, and slender patients, (11) although $\mathrm{CT}$ is less operator dependent than sonography. ${ }^{(10,12)}$ It may help in surgical planning, ${ }^{(10,13)}$ has sensitivity and specificity rates of $93 \%$ and $92 \%$, respectively ${ }^{(12,13)}$, can safely exclude appendicitis ${ }^{(12)}$ without CT rates of appendectomy with normal findings (negative appendectomies) was of 13.4 to $33 \%{ }^{(4,7,10,13-15)}$.
On the other hand there are authors claiming that it has no significant contribution to the diagnosis of acute appendicitis, and that they in fact delay treatment and therefore result in increased perforation rates with negative appendectomy rates reaching up to $20 \%$ and the rates of negative appendectomy have remained unchanged ${ }^{(4,8)}$.

We aim to determine the alternative diagnosis for the pain in which appendicitis was considered and to find the incidence of negative appendectomies in our practice.

\section{Patients and methods}

An observational study including 558 patients, who underwent appendectomy at $\mathrm{Al}$ Sulaimaniyah Teaching Hospital (STH) from the $2^{\text {nd }}$ of January to the $30^{\text {th }}$ of June 2009. Only patients who underwent urgent appendectomy and specimen subjected to tissue examination were included. All the patients were operated for appendicitis by open appendectomy on the basis of history, physical findings, relevant clinical data, investigations, plain abdominal radiography and ultrasound. The Ethics committee of $\mathrm{Al}$ Sulaimaniyah University - Medical College approved the research protocol, and written informed consent was obtained from all patients.

Demographic data regarding age, gender, occupation, duration, details of symptoms and clinical signs of acute appendicitis were recorded

Baseline laboratory assessment included leucocytes count and urine analysis, imaging including; plain radiography of abdomen was performed in 89 patients and ultrasonography was performed in 480 (84\% of) patients and the remaining patients $78(13.97 \%)$ underwent surgery without diagnostic ultrasonography 
because they were admitted during the night when the ultrasound is not available.

All the patients were told not to take anything orally for 4 hours. After the decision was made by the on call surgeon, and then the patients were seen by anesthetist doctors. During induction of anesthesia prophylactic antibiotics given as $1 \mathrm{~g}$ Ampicillin-Cloxacillin (or Ceftriaxone when the patient was allergic to penicillin), and $80 \mathrm{mg}$ (or the dose was adjusted to the weight in children) of gentamicin intravenously.

Through right sided grid iron incision (3-7 $\mathrm{cm}$ ), centered on the McBurney point, formal minilaparotomy was done; peritoneal cavity was inspected for any fluid, pus, blood, Meckel's diverticulum, ovarian pathology, etc. Caecum was identified, the appendix was found, retrograde appendectomy was done in most of the cases $549(98.38 \%)$ and ante grade for the others.

Appendices were labeled acutely inflamed when, macroscopically there were intravascular injection of mucosa, fibrinous or purulent film, edematous or necrotic changes of the wall and blood or pus on opening the appendix. ${ }^{(15)}$

All excised appendices or any excised tissue were sent for histopathology. Patients were discharged on the base of day case surgery when they fulfilled discharging criteria as following: stable vital signs, apyretic: no wound or airway problems, tolerating diet, and established autonomy at discharge, possession of a telephone, suitable home accommodation and adequate home support upon discharge ${ }^{(16)}$, to report on need, or after 7 days.

Histopathological criteria of acutely inflamed appendix were granulocytic invasion of the mucosa (erosive), deeper lesions to the submucosa (erosive or ulcerated), or into the muscular wall (ulcer or inflammation). Perforating appendicitis was diagnosed in cases of periappendiceal abscess, gangrene, or when lesions penetrated the wall, and were verified macroscopically. Scarring and specific lesions were not considered as acute appendicitis. ${ }^{(17)}$
The data were analyzed using SPSS version 16, A P-value of less than .05 was considered to indicate statistical significance.

\section{Results}

A total of 558 patients had appendectomy for clinically diagnosed acute appendicitis over 6 months at Al Sulaimaniyah Teaching Hospital. Most of the patients were young between 2040 years age with median age of $22 \pm 7.7$ years. Three hundred and five patients $(54.66 \%)$ from sum of 558 patients were females, two hundred fifty three $(45.34 \%)$ patients were males and with female to male ratio 5/4.

More than three quarters of the patients presented within 6 hours from the onset of abdominal pain and three quarters underwent operations within 6-12 hours and the rest within first 24 hours after admission, (Table 1). Only $491(87.99 \%)$ patients presented with right iliac fossa pain, while the rest had generalized or central abdominal pain, and $312(55.91 \%)$ had tenderness in the right iliac fossa. More than three quarters of the patients $451(80.82 \%)$ had nausea, while $257(46.05 \%)$ of the patients had vomiting before the onset of the pain and $30(5.37 \%)$ patients had vomiting after the onset of pain. Three hundred and sixty eight (65.94\%) patients were anorexic, $62(11.11 \%)$ had dysuria and only $89(15.94 \%)$ patients had mild pyrexia up to 38.2 degree centigrade.

Histological normal appendix was present in $178(31.89 \%)$ patients, $61(10.93 \%)$ of them were males and $117(20.96 \%)$ were females (Table 1) (P-value $=0.0259)$.

Among 558 patients who were suspected clinically of having acute appendicitis, intraoperative finding revealed that 206 $(36.92 \%)$ patients had acutely inflamed appendix, $113 \quad(20.25 \%)$ suppurative appendicitis, $32 \quad(5.73 \%)$ gangrenous appendicitis, 12 (2.15\%) had perforated appendix . One patient had Carcinoid tumor in the base of the appendix and in $7(1.25 \%)$ cases there were Enterobeous Vermicularis (E.V) found inside the lumen of the acutely inflamed appendices, (Table 2).

Fifty nine (10.03\%) patients were diagnosed intraoperative by naked eyes as normal appendix, 18 of them showed pathological 
changes on the histological examination. While $14(2.51 \%)$ appendices labeled during the operations as appendicitis were histopathologically normal.

Other pathologies presented in patients with macroscopically normal appendices, included $35(6.27 \%)$ patients had purulent peritoneal fluids occurring in young female with tuboovarian infections, $12(2.15 \%)$ patients had mesenteric lymphadenitis and 37 (6.63\%) of the patients had rupture graafian follicles (Table 3).
Some patients with normal appendices had co-accidental normal findings like $14(2.50 \%)$ of female patients had uncomplicated ovarian cyst in those underwent operation without ultrasonographic examination of the abdomen, $4(0.71 \%)$ non-inflamed Meckel's diverticulum. Gynecologist was consulted about tuboovarian infections, ovarian cysts and rupture graafian follicles and, appendices from all these patients were removed.

Table (1): Negative appendectomies and alternative diagnosis; difference in gender, time of appendectomy, in each age group with their complications.

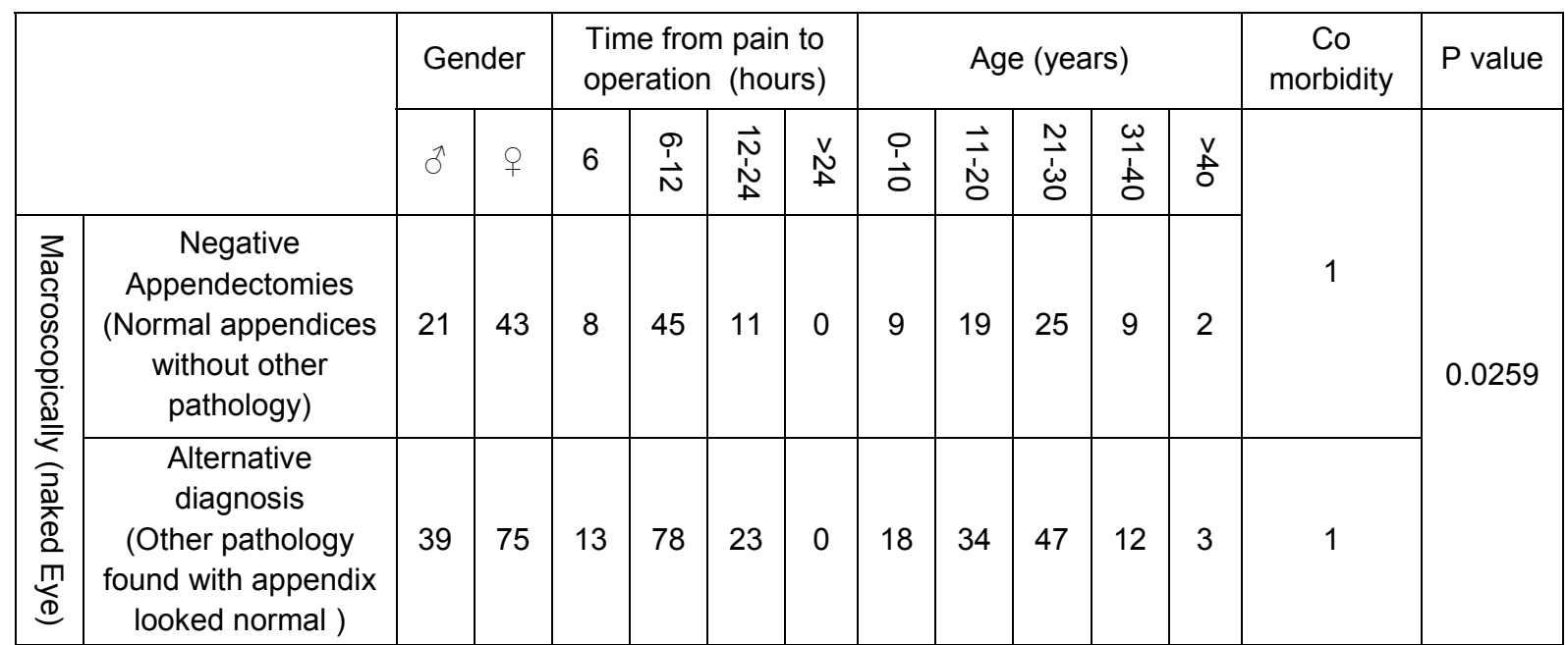

Table (2): Histopathological results of all the patients underwent open appendectomy.

\begin{tabular}{|l|c|}
\hline \multicolumn{1}{|c|}{ Diagnosis } & $\begin{array}{c}\text { Frequency no. } \\
\text { and (\%) }\end{array}$ \\
\hline Acute appendicitis & $206(36.92 \%)$ \\
\hline Normal appendix & $178(31.89 \%)$ \\
\hline Suppurative appendicitis & $113(20.25 \%)$ \\
\hline Gangrenous appendix & $32(5.73 \%)$ \\
\hline Perforated appendicitis & $12(2.15 \%)$ \\
\hline $\begin{array}{l}\text { Acutely inflamed appendices } \\
\text { obstructed with E.V }{ }^{*}\end{array}$ & $7(1.25 \%)$ \\
\hline Carcinoid at the base of appendix & $1(0.179 \%)$ \\
\hline Total & $558(100 \%)$ \\
\hline
\end{tabular}

*Enterobeous Vermicularis.
Table (3): Alternative diagnosis were found in normal appendices.

\begin{tabular}{|l|c|}
\hline \multicolumn{1}{|c|}{$\begin{array}{c}\text { Findings in the patients with } \\
\text { normal appendix }\end{array}$} & $\begin{array}{c}\text { Frequency } \\
\text { no. and (\%) }\end{array}$ \\
\hline Rupture Graafian follicle & $37(6.63 \%)$ \\
\hline $\begin{array}{l}\text { Purulent peritoneal fluid (pelvic } \\
\text { infection, tuboovarian infections) }\end{array}$ & $35(6.27 \%)$ \\
\hline Mesenteric lymphadenitis & $12(2.15 \%)$ \\
\hline
\end{tabular}

\section{Discussion}

The present work showed that more than $60 \%$ who had normal appendix were females and their mean age was $18 \pm 5.6$ years. The findings are in the line with the reported difficulties in female adolescence and young females ${ }^{(2,12,}$ 13, 18-20). The accuracy of a clinical diagnosis of acute appendicitis based on patient's history 
and physical examination ranges from $70 \%$ to $84 \%$. In women of childbearing age, this figure decreases to $60-68 \%$ because of the overlap of symptoms from acute gynecologic abnormalities ${ }^{(2)}$.

In the current study results showed that the incidence of negative appendectomy to be 178 $(31.89 \%)$ which is comparable to recently published literatures, declaring that rates of appendectomy with normal findings (negative appendectomies) were in the range of 13.4 to $33 \%^{(4,7,10,13-15,21)}$. Appendectomy for a normal appendix is associated with both morbidity and mortality. ${ }^{(21,22)}$ Although the morbidity and mortality are of the same quality, but with higher frequencies i.e., up to $5 \%$ of patients will develop intestinal obstruction following surgery for a normal appendix. ${ }^{(23)}$

The diagnostic tools like white cell counts, urine analysis and ultrasonography have not been shown conclusively to improve the outcome in terms of negative finding on appendectomy. ${ }^{(3,4,5,12,13,24,25)}$

The surgeons who did the operations considered all the patients $(n=558)$ to have acute appendicitis, while pathological results showed 178 excised appendices to be normal. One of the reasons for this finding may be that the majority of surgeons favor early operation. It was stated that negative appendectomy is higher among patients who received immediate surgery after admission to a hospital. ${ }^{(8,26)}$ furthermore a recent retrospective study found no significant differences in complications between early (less than 12 hours after presentation) and late (12-24 hours) appendectomy. ${ }^{(8)}$

In this work all $(n=588)$ appendices were removed, even when they look macroscopically normal. The points of defense are, first endoluminal appendicitis occurs in $11-58 \%$ of apparently normal appendices which were removed Secondly it is accepted generally to remove normal appendices during open appendectomies. ${ }^{(8,27)}$ The third point is that normal-looking appendices have a $22 \%$ chance of being inflamed on further sophisticated investigations. (18) It is also reported that children underwent appendectomy for either infected or normal appendix have reduced chance of developing ulcerative colitis. ${ }^{(27)}$

During appendectomy, 14 appendices were labeled by naked eyes to be acutely inflamed, but histopathology showed them to be normal appendices. Five of which were associated with tubo-ovarian infection, and three were associated with rupture graafian follicles, while the rest have no any alternative pathology. Jane $\mathrm{E}$. et al, gave an explanation for that the appendix in some patients with colonic diverticulitis, colitis, or pelvic inflammatory disease had a secondary edema or serosal inflammation. (28)

There was one case of carcinoid tumor presented as acute appendicitis, it was evident as yellowish small oval mass $(8 \mathrm{~mm} \times 4 \mathrm{~mm})$ in the base of the appendix, this presentation is not going in line with literature. Studies were reporting that carcinoid tumors were not evident macroscopically. The incidence $(0.17 \%)$ out of 558 patents also higher than what found in the literature $(0.1 \%)$ out of 1000 patients ${ }^{(29,30)} \mathrm{P}$-value $=0.001$.

In the current work seven patients had Enterobeous Vermicularis in appendicular lumen, when histological results showed inflamed appendix. This is comparable to literature "Enterobeous infection is often associated with acute appendicitis and perforation of an inflamed retrocaecal appendix" ${ }^{(10,18,31)}$.

Imaging will help in accuracy of diagnosis and decreasing negative appendectomy, it also may detect alternative diagnosis in patients with features of acute appendicitis. It may be necessary to use imaging to raise the accuracy of clinico-laboratory diagnosis of acute appendicitis, but not routinely, saving for special groups with difficulty in clinical diagnosis of acute appendicitis.

\section{The limitations of the work}

One of the limitations of the current work is that, we haven't started diagnostic laparoscopy in our centre, which may significantly reduce the rate of removal of histo-pathologically normal appendices, $(18,19)$ accordingly we are not able to discuss the effect of laparoscopy on reducing negative appendectomies. Another limitation is the CT 
of the abdomen not ordered although it is available in restricted time in our Emergency Department (from 08.00 to1400). This makes us have no wide concept of the effect of the CT scan on reducing negative appendectomy, although there are studies claiming that CT have been used to diagnose appendicitis with no additional diagnostic specificity. $(2,12,13,32,33)$ Also it needs ionizing radiation; it is not routinely available at all hours and has false negative results as high as $15 \%{ }^{(3,4,7,11-13,28)}$ The effect of ionizing radiation may be a drawback especially the patients with uncertain clinical diagnosis, who need a CT usually are adolescence or young child bearing ladies $(2,12,13,18,19,28)$.

\section{Conclusion}

Normal appendices were found in $32 \%$ of the patients, more frequently in young female patients, undergoing early (within 6 hrs since the pain) appendectomy, with the most common alternative diagnosis of tubo-ovarian infections.

\section{Acknowledgements}

We are grateful to Dr. Adnan Hamawandi Professor of pediatrics, for his statistical guidance, and to all medical and paramedical staff at the Emergency Department of AlSulaimaniyah Teaching Hospital for their technical help.

\section{References}

1. Treutner $\mathrm{KH}, \quad$ Schumpelick V. Epidemiology of appendicitis. Chirurg 1997; 68:1-5.

2. Nikolaidis $\mathrm{P}, \mathrm{H}$ wang $\mathrm{CM}$, Miller FH. The Nonvisualized Appendix: Incidence of Acute Appendicitis When Secondary Inflammatory Changes Are Absent, AJR 2004;183: 889.

3. Mittal VK, Goliath J, Sabir M, et al. Advantages of Focused Helical ComputedTomographic Scanning With Rectal Contrast Only vs Triple Contrast in the Diagnosis of Clinically Uncertain Acute Appendicitis, ARCH SURG 2004; 139:495.

4. Bursalı $A$, Araç $M$, Öner $A Y$, et al. Evaluation of the normal appendix at low- dose non-enhanced spiral CT, Diagn Interv Radiol 2005; 11:45-50.

5. Kamran H, Naveed D, Nazir A, et al. The role of white cell count and C-reactive protein in the diagnosis of acute Appendicitis, J Ayub Med Coll Abbottabad 2004; 16(3):17-9.

6. K Haider, Naveed D, Nazir A, et al. Role of total leukocyte count in diagnosis of acute appendicitis. J Ayub Med Coll Abbottabad 2008;20(3):70-72.

7. Ohmann C, Franke C, Yang Q, et al. Clinical Benefit of a Diagnostic Score for Appendicitis. ARCH SURG 1999; 134: 993-996.

8. Humes D J, Simpson J. Acute appendicitis, BMJ 2006; 333:530.

9. Memisoglu K, Karip B, Mestan M, et al., The value of preoperative diagnostic tests in acute appendicitis, retrospective analysis of 196 patients, World Journal of Emergency Surgery 2010; 5:5.

10. Benjaminov $F$, Atri $M$, Hamilton $P$, et al. Frequency of Visualization and Thickness of Normal Appendix at Nonenhanced Helical CT, Radiology 2002; 225(2): 400406.

11. Seo H, Lee K H, Kim H J. Diagnosis of Acute Appendicitis With Sliding Slab RaySum Interpretation of Low-Dose Unenhanced CT and Standard-Dose IV Contrast-Enhanced CT Scans. AJR 2009; 193.

12. Koch A, Marusch F, Schmidt $U$, et al. Appendicitis in the last decade of the $20^{\text {th }}$ century. Zentraldl Chir. 2002; 127:290-6.

13. Ganguli S, Raptopoulos V, Komlos F, et al. Right Lower Quadrant Pain: Value of the Nonvisualized Appendix in Patients at Multidetector CT, Radiology: 2006; 1( 241):175-180.

14. Birnbaum BA, Wilson SR. Appendicitis at the Millennium. Radiology.2000; 215:337348.

15. khairy G. Acute appendicitis of a normal appendix still excisting and can we reduce its rate?. The Saudi J. of Gastroentrology 2009; 3(15): 167-170. 
16. Deedivitis R.A, EG JR, et al. Analysis of safety of short-stay thyroid surgery Acta Otorhinolaryngologica 2009; 29:326-330.

17. Langenscheidt $P$, Lang C, Pu"schel W. High Rates of Appendicectomy in a Developing Country: an Attempt to Contribute to a more Rational use of Surgical Resources, Eur J Surg. 1999; 165: 248-252.

18. Hussain $A$, Mahmood $H$, Singhal $T$, et al. What is positive appendicitis? A new answer to an old question. Clinical, macroscopical and microscopical findings in 200 consecutive appendectomies. Singapore Med J. 2009; 50(12): 1145.

19. Delaney C.P, O'Connell P.R. Towards consensus on the fate of the normal appendix at laparoscopy for suspected appendicitis, I.J of Medical Sciences1999; 168(2): 109-110.

20. Khalid K, Ahmad N, Farooq O, et al. Appendicitis - laboratory dependence can be misleading: audit of 211 cases, J Coll Physicians Surg PakAcute 2001; 11(7): 434-7.

21. Kimberly Garcia, Marta HernanzSchulman, Debbie Lee Bennett, Suspected Appendicitis in Children: Diagnostic Importance of Normal Abdominopelvic CT Findings with Nonvisualized Appendix, Radiology 2009; 250: $2,531$.

22. Mutter D, Vix M, Bui A, et al. Laparoscopy not recommended for routine appendectomy in men: Results of a prospective randomized study. Surgery 1996; 120:71-4.

23. Shafi SM, Afsheen M, Faroog A. et al. Total leukocyte count, C-reactive protein and neutrophil count: diagnostic aid in acute appendicitis. Saudi J of GIT 2009; 15(2):117-20.

24. Jones $A E$, Phillips AW, Jarvis $J$, et al. The value of routine histopathological examination of appendicectomy specimens. BMC Surgery 2007; 7:17.
25. Ahmed HO. Role of ultrasound in patients with high clinical suspicion of acute appendicitis. Journal of Zankoy Sulaimani, September 2006; 9(1): 107-114.

26. Wen S W, Demissie K, August D, et al. Level of aggregation for optimal epidemiological analysis: the case of time to surgery and unnecessary removal of the normal appendix, J Epidemiol Community Health 2001; 55:198-203.

27. Kaplan G G, Pedersen B V, Andersson R $E$, et al. Study in Sweden and Denmark appendectomy: a population-based cohort Gut 2007; 56: 1387-1392.

28. Turner $\mathrm{E} J \mathrm{H}$, Lightwood R. Management of the 'Normal' Appendix during Laparoscopy for Right Iliac Fossa Pain, World Journal of Laparoscopic Surgery 2009; 2(2):15-17.

29. Deans GT, Spence RA. Neoplastic lesions of the appendix. Br J Surg 1995; 82(3): 299-306.

30. Hof K, van der Wal H, Kazemier G, et al. Carcinoid Tumour of the Appendix: An Analysis of 1,485 Consecutive Emergency Appendectomies. J Gastrointest Surg. 2008; 12(8): 1436-1438.

31. Khan O A, Morhan A, Jegatheeswaran S, et al. Routine Pathological Analysis of Appendicectomy Specimens - Is it Justified ?. Acta chir belg, 2007; 107:529530.

32. Carmelita A, Maxim S. Influence of Imaging on the Negative Appendectomy Rate in Pregnancy As Surg. 2008;12:4650.

33. Marcia LM, David Z, Darshani N, et al. Negative appendectomy rate: Influence of CT scans. Am Surg. 2005; 71:803-808. 